\title{
AN APPROACH TO IDENTIFY AND ESTIMATE THE BONDING OF COPPER AND ALUMINUM POWDERS
}

\author{
Volume 6, Issue 2, July-December- (2015), pp. 01-18 \\ Article ID: 30320150602001 \\ International Journal of Design and Manufacturing \\ Technology (IJDMT) \\ (C) IAEME: https://iaeme.com/Home/issue/IJDMT? Volume=6\&Issue=2 \\ ISSN 0976 - 6995 (Print) \\ ISSN 0976 - 7002 (Online) \\ https://doi.org/10.34218/IJDMT.6.2.2015.30320150602001
}

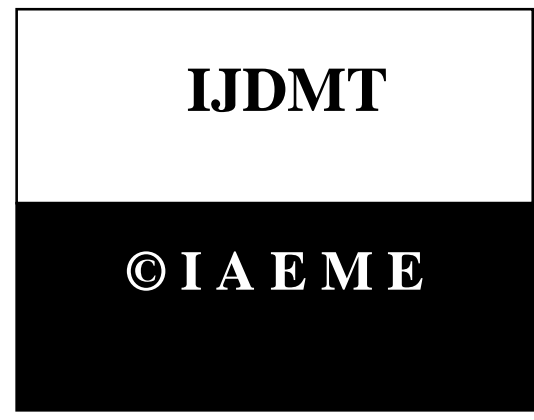

\section{Karan Singh $^{1}, \quad$ Dr. Mohammad Israr ${ }^{2}$}

${ }^{1}$ Research Scholar, Department of Mechanical Engineering, O.P.J.S. University, Churu, Rajasthan, India

${ }^{2}$ Principal, Dungarpur College of Engineering and Technology, Dungarpur, Rajasthan, India

\section{ABSTRACT}

Ultrasonic powder consolidation (UPC) is a novel rapid, full-density powder consolidation process in which metal powders confined in a die under uniaxial loading is subjected to ultrasonic vibration at low temperature for a few seconds or less. In this research, copper powders with dendritic and spherical morphologies and an aluminum powder with spherical morphology were subjected to UPC under various conditions to investigate the effects of the process variables on the densification and metallurgical bonding of the compact. An ultrasonic washing test, developed in this research, was used to determine the extent of densification and bonding achieved in specimens consolidated under systematically varied UPC conditions. Hardness testing was also employed as a supplementary means for the assessment of compact density in both as-consolidated and ultrasonically washed states. The degree of metallurgical bonding was also qualitatively assessed from the fracture surfaces of manually broken specimens. With the dendritic and spherical copper powders, the minimum consolidation temperature, time and uniaxial pressure required for nearly full densification were determined to be $450{ }^{\circ} \mathrm{C}, 4 \mathrm{~s}$ and $84 \mathrm{MPa}$, respectively. The best conditions were $500{ }^{\circ} \mathrm{C}, 4 \mathrm{~s}$ and $100 \mathrm{MPa}$ for both copper powders. Dendritic-powder specimens exhibited better]

Densification and bonding than spherical-powder specimens above $450{ }^{\circ} \mathrm{C}$. However, below $450{ }^{\circ} \mathrm{C}$, the spherical powder produced better results, due probably to its higher packing geometry and repacking under the ultrasonic vibrations. With the spherical aluminum powder, specimens with best densification and bonding were obtained under the conditions of $400{ }^{\circ} \mathrm{C}, 2.5 \mathrm{~s}$ and $80 \mathrm{MPa}$. Compact densification generally requires a good amount of powder deformation. In UPC, this occurs very quickly in a fraction of a second if consolidation temperature is sufficiently high. However, a high degree of compact densification does not necessarily assure good metallurgical bonding. Bonding must be preceded by the formation of nascent metal-to-metal contact of powder particles, which requires good compact densification. Thus, densification is only a necessary condition for bonding. For the copper compacts, metallurgical bonding, at a given temperature, increased with increasing consolidation time, indicating that bonding is a thermally activated 


\section{An Approach To Identify and Estimate The Bonding of Copper and Aluminum Powders, Karan Singh, Dr. Mohammad Israr,}

(diffusional) process. Densification of dendritic powder produced more fresh metal surface and hence higher degrees of bonding. The bonding in the aluminum compacts, however, followed densification more closely, reflecting the higher homologuos temperatures (up to 0.72 of the melting point in $\mathrm{K}$ ).

Key Words: Bonding of Copper and Aluminum, Ultrasonic powder.

\section{INTRODUCTION}

\subsection{Overview}

Ultrasonic welding (USW) is a solid-state joining process that facilitates rapid-joining of similar or dissimilar materials at room temperature. USW has been used extensively in industry for various applications like electronics, semiconductor, and automotive industries for rapid joining of metal wires, cables, and sheets. Ultrasonic powder consolidation (UPC) [2] is a USW technique that applies to the consolidation of metallic powders. Conventional techniques for the consolidation of powders generally require a two-step process, cold compaction and sintering. The first step forms a green compact which usually has a high amount of porosity, and the second step facilitates compact densification and metallurgical bonding which requires heating the compact to a high enough temperature, generally well above half of the melting point of the material on homologous scale. Previous research on vibratory compaction resulted in green compacts that require subsequent sintering. However, it has recently been shown that UPC can create fully dense Al consolidates without subsequent sintering within a fraction of a second. Another recent research on applying UPC to the consolidation of $\mathrm{Cu}$ and $\mathrm{Cr}$ powder mixtures has shown that fully dense $\mathrm{Cu}-\mathrm{Cr}$ composites could be produced at low pressures and temperatures in a short vibration time . As a result, this new technique, UPC, has shown its capability on powder consolidation and further work 2 is required to find a processing window for the full consolidation of metal powders and also to test the quality of consolidated materials.

\subsection{Objectives}

This study focused on the consolidation of $\mathrm{Cu}$ and $\mathrm{Al}$ powders with the objectives listed below:

1. Consolidation of $\mathrm{Cu}$ powders with dendritic and spherical morphologies by UPC under various conditions.

2. Consolidation of Al powders by UPC under various conditions.

3. Determination of the processing window for full metallurgical consolidation of all $\mathrm{Cu}$ and $\mathrm{Al}$ powders.

4. Analysis of the microstructure of produced specimens by optical microscopy and scanning electron microscopy.

5. Analysis of produced specimens in terms of porosity, hardness and ductility by ultrasonic washing tests, Vickers micro-hardness tests and bending tests respectively. 


\section{An Approach To Identify and Estimate The Bonding of Copper and Aluminum Powders, Karan Singh, Dr. Mohammad Israr,}

\section{BACKGROUND}

\subsection{Powder Consolidation Techniques}

Powder metallurgy (PM) is a widely used technique to produce metal products and metal composites. Generally, it consists of four major steps: (1) production of powders, (2) blending or mixing, (3) pressing powders into green compacts which still contain porosity, (4) formation of a bulk material by a consolidation process. In a conventional method, green compaction is normally achieved by cold pressing, while consolidation is obtained by sintering at an elevated temperature. Another widely used method is hot isostatic pressing (HIP) in which powders vacuum-encapsulated in a metal container is held under isostatic pressure at an elevated temperature for a sufficient amount of time which depend on the material and selected temperature. Generally, a complete cycle of HIP takes 12 to 24 hours for full consolidation at $80 \%$ of the absolute melting temperature. Since the compaction and subsequent sintering processes are time consuming, there is a vast amount of research in the field of high strain-rate processes [9-21] conducted to minimize the processing time. However, these methods still require the powder to be compacted prior to deformation processing. The most commonly employed high strain-rate powder consolidation techniques are powder forging, rolling and extrusion, equal channel angular pressing (ECAP), and shock wave consolidation. Although, materials produced by these techniques can generally achieve more than $99 \%$ density, they may still need to be further processed in order to improve mechanical properties. Extrusion is generally a two-step process where the powders are first cold pressed into a can and subsequently extruded at room temperature or an elevated temperature after evacuation and sealing. Many studies have been done on the extrusion of $\mathrm{Al}$ and $\mathrm{Al}$ alloy powders at temperatures from room temperature to $773 \mathrm{~K}$ [17-19]. By conducting cold isostatic pressing at $350 \mathrm{MPa}$ and following hot extrusion at $773 \mathrm{~K}$ together, Lee et al obtained full density Al-Le alloy composites. The shock wave consolidation process produce a bulk material by passing a shock wave through the powder and the necessary shock wave is generated by detonating an explosive. In 1991, a review published by Rosato, Vreeland, Jr, and Prinz summarized various studies covering this techniques. Jin Yuan et al. consolidated Al-Li alloy powders by this method and they concluded that the shock wave could break up the surface oxide layer and resulted in compacts with densities above $98 \%$ while preserving the initial microstructure of the powders. However, they also stated an abnormal softening in comparison with the original powders.

\subsection{Ultrasonic Welding of Metals}

As a solid-state joining process, USW produces metallurgical bonding by the application of high-intensity vibration in the ultrasonic frequencies when used for metals, combined with normal compression of the materials [22]. The friction forces between the parts or powders, sonotrode, the anvil, the die and the punch prevent the slippage, such that the vibratory energy is efficiently transmitted and dissipated at the weld interface by high frequency scrubbing action. This highly localized interfacial slip initially causes disruption and dispersion of surface films like oxides, permitting fresh metallic contact and formation of micro-welds shown in Figure 2.1 Further processing results in the coalescence of microwelds until a fully developed weld zone is realized. Continued application of the vibration causes high strain-rate elastic-plastic deformation, generating modest heating with a transient maximum at $35-50 \%$ of the melting point. Furthermore, these highly localized high strain rate 


\section{An Approach To Identify and Estimate The Bonding of Copper and Aluminum Powders, Karan Singh, Dr. Mohammad Israr,}

shear strains have been shown to create large concentration of excess vacancies in the parent metals and high dislocation densities. This creates a fine-grained cold-worked structure, recrystallization, phase transformations and atomic diffusion across the bond. An extraordinary feature of USW is its capability for both monometallic and bimetallic welding like metal bonding to polymers and ceramics. In particular most metals, including aluminum, copper, nickel, titanium, iron and steel and precious metals and most of their alloys can be readily welded to themselves and to others. Another advantage of USW is its short welding time and limited pressure and temperature, preventing damage to plastics and semiconductors, as well as joint deformation and residual stresses. As a result, ultrasonic bonds which are made properly exhibit shear strength, hardness, high temperature behavior and corrosion resistanc comparable to those of normal materials. In addition, weld quality is not sensitive to original materials and surface conditions like oxide films and coatings, and usually requires no protective atmosphere. Finally, there is no need for special health, safety precautions and environmental hazards. The first studies and publications on ultrasonic welding appeared in 1955 and 1956. where the design of ultrasonic welding equipment for the welding of aluminum, copper, steel and some alloys and along with initial metallurgical studies were presented. In the early 1960's after the establishment of the USW equipment, researchers were able to focus on the fundamentals of the joining mechanism. Jones et al. published a phenomenological treatise in which the weldability of aluminum, copper, nickel and stainless steel was investigated. In 1965, another treatise on USW was published where the formulation of contacting and oscillating spheres, which was verified by the experimental results in was used to estimate the energy dissipation during ultrasonic cycles. According to , it was proposed that adhesion first occurred at micro-slip regions at the interface, followed by rapid temperature rise produced by energy dissipated through hysteresis, which resulted in softening, plastic flow, enhanced interfacial diffusion and increase in total micro-weld areas. The effect of high intensity ultrasound on the deformation of metals was reported in 1966 and 1970. Standard tensile test samples of aluminum, zinc and steel were tested while ultrasonically vibrating the samples at varying degrees of intensity. The results showed immediate reductions in the elastic modulus and yield strength of the materials during the application of ultrasonic vibration when a threshold intensity was reached. Another threshold intensity was found above which permanent strain hardening occurred. However, the calculations indicated that the acoustic stresses were not sufficient to cause dislocation glide and subsequent hardening. The first comprehensive analysis of wire bonding investigated the effects of clamping load on bond quality and noted that the weld strength increased up to a certain degree by bonding, but started to decrease after the wire degraded on the perimeter of the weld area, therefore giving the first explanation to the widely observed trend. The motion of the welded parts was observed by a laser interferometer and high-speed recording techniques. The results indicated that in good quality welds, little relative motion was observed between the parts. Simultaneous measurement of interface temperature and interdiffusion was first performed by Kulemin et al. for aluminum copper pairs. The concentration profiles obtained by electro micro-probe analysis were related to diffusivities. The results indicated diffusion enhancements by seven orders of magnitude and it was considered that this was due to alternating stresses and strains. Enjo et al.investigated the effect of ultrasonic vibration on the diffusion welding of aluminum and they observed that bond strength increased significantly due to oxide breakup at the interface. In recent studies, Yadav and Doumanidis and Gao focused on the modeling of USW, where finite element methods were employed to predict strain fields around the weld interface, which were verified with strain 


\section{An Approach To Identify and Estimate The Bonding of Copper and Aluminum Powders, Karan Singh, Dr. Mohammad Israr,}

measurements. In 2005, the study result from Gunduz et al. reported enhanced inter-diffusion and melting point depression during elevated temperature USW of aluminum zinc pairs. They provided the first thermodynamic model that included the effects of excess vacancies induced by high strain rate deformation during USW on solid phase stabilities.

\subsection{High Rate Plastic Strain Effects}

Since the majority of ultrasonic metal studies are concerned with enhancing weld formation and optimizing processing parameters for industrial welding applications, most welding is performed at room temperature. As a result, most of the literature describes ultrasonic metal welding as a low temperature, solid-state joining process that creates metallurgical bonding without melting. However, there are varying opinions about the fundamental mechanisms of ultrasonic welding of metals. For example, some of them indicate that enhanced interdiffusion and local melting may occur during ultrasonic welding which can be attributed to high strain rate plastic deformation and increase in vacancy concentration $(\mathrm{Xv})$. Non-conservative motion of jogs on screw locations can produce increased $\mathrm{Xv}$ that has a drastic effect on the thermodynamic stability of the solid solutions. In 1966, Langenecker performed tensile tests to study the effects of ultrasound on deformation characteristics of metals. In this literature, Langenecker discussed two pronounced effects of ultrasound on metals: acoustic softening which occurs during application of ultrasound is an apparent reduction in shear stress necessary for plastic deformation and subsequent acoustic hardening which is observed after ultrasound application. Langenecker first described the mechanism of ultrasonic softening as acoustic energy being absorbed at dislocation sites, increasing dislocation amplitudes until freeing them from pinned equilibrium positions, forcing dislocations to move in a preferred direction. Then Langenecker attributed the acoustic hardening to dislocation multiplication during intense ultrasonic irradiation. A TEM image (Figure 2.1) of aluminum after ultrasonic irradiation showing increased dislocation density with sub-boundaries consisting of dislocation networks. Before ultrasonic irradiation, the sample was free of such sub-boundaries and had a relatively low dislocation density (< $109 \mathrm{~m}-2)$.

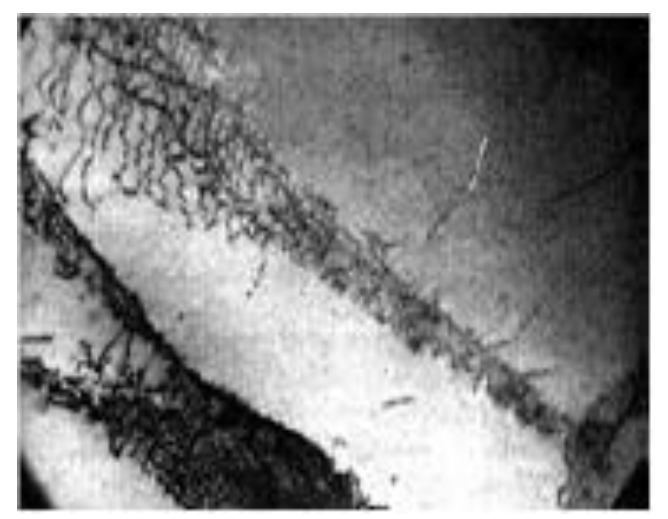

Figure 2.1: TEM image of aluminum specimen under ultrasonic irradiation [45].

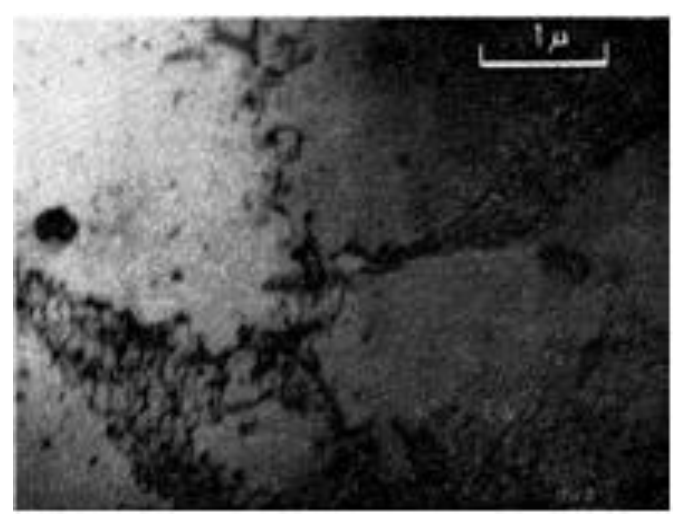

Figure 2.2: Dislocation networks in copper specimen under ultrasonic fatigue test

Awatani and Katagiri also performed ultrasonic fatigue tests with aluminum and analyzed the microstructure by TEM. They observed jogs and mentioned that vacancies can 


\section{An Approach To Identify and Estimate The Bonding of Copper and Aluminum Powders, Karan Singh, Dr. Mohammad Israr,}

be generated due to the non-conservative motion of jogs on screw dislocations. The vacancies may sink to grain boundaries or edge dislocations leading to climb, but Awatani and Katagiri observed that some vacancies may condense to form loops and voids (Figure 2.3). The appearance of loops and voids indicates that a large number of vacancies were created by the ultrasonic irradiation.

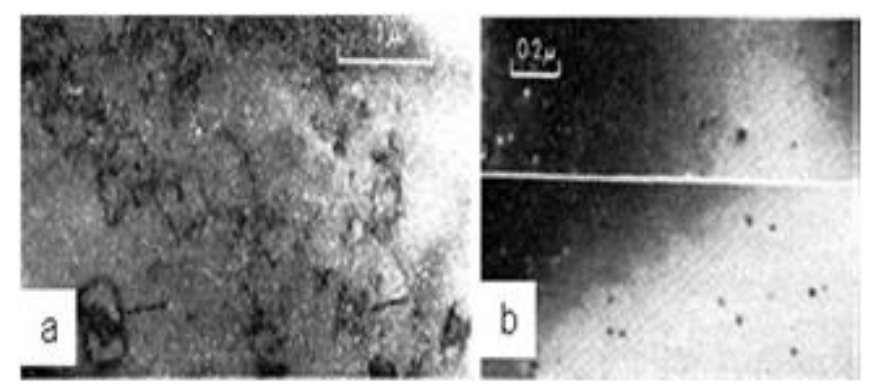

Figure 2.3: (a) Dislocation loops and (b) voids appear in aluminum specimens under ultrasonic irradiation

The process of ultrasonic softening is most likely due to the production a large concentration of vacancies above the thermal equilibrium value. Hull discusses the process of creating strain-induced vacancies [54], in which a critical applied stress is required for dislocation movement. During high rate plastic deformation, many screw dislocations acquire vacancy producing jogs as shown in the schematic in to create a large concentration of vacancies. If the glide plane of the dislocation is different from that of the jog, the screw location moves forward and takes jogs with it by a non-conservative process of climb.

\section{EXPERIMENTAL PROCEDURE}

\subsection{Materials}

The powders used in this research are (1) electrolytic $\mathrm{Cu}$ powders (>99\%) and spherical $\mathrm{Cu}$ powders (>99\%), 8-12 $\mu \mathrm{m}$ and 6-10 $\mu \mathrm{m}$ in size, respectively, both of which were supplied by Fukuda Metal Foil and Powder Co. Ltd., Japan, and (2) Al powders, 7-15 $\mu \mathrm{m}$, (Figure 3.2) supplied by Alfa Aesar. In this research, the electrolytic $\mathrm{Cu}$ powder is called the "dendritic $\mathrm{Cu}$ powder" because of its morphology.
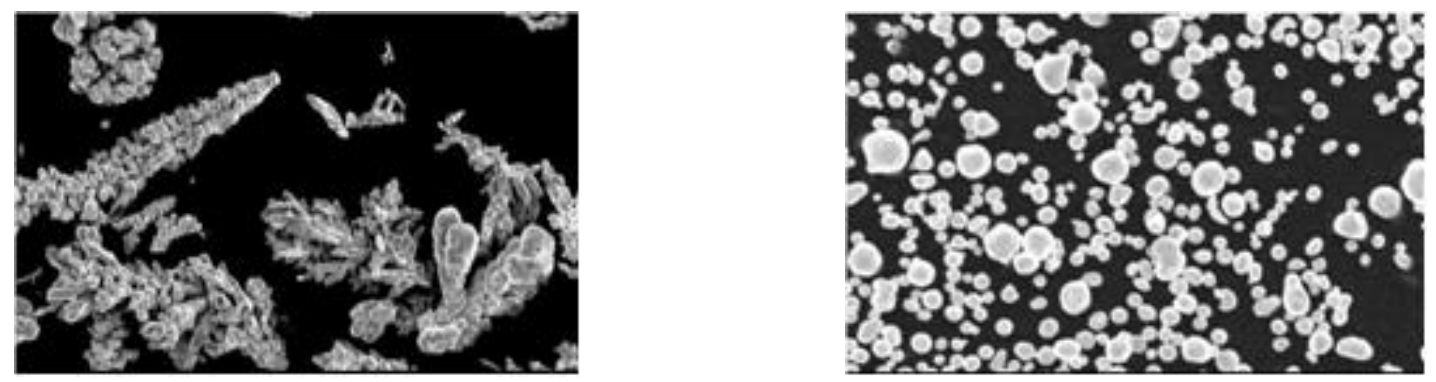

Figure 3.1: SEM pictures of as-received (a) dendritic $\mathrm{Cu}$ powder (b) spherical $\mathrm{Cu}$ powder. 


\section{An Approach To Identify and Estimate The Bonding of Copper and Aluminum Powders, Karan Singh, Dr. Mohammad Israr,}

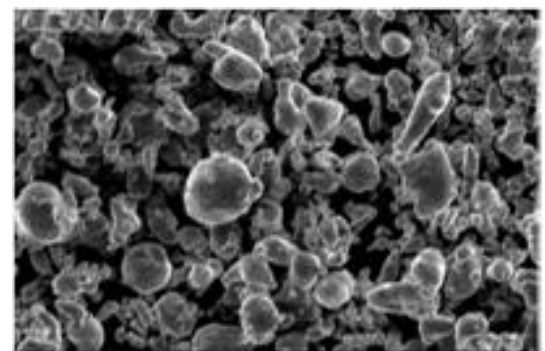

Figure 3.2: SEM pictures of as-received $\mathrm{Al}$ powder.

\subsection{Ultrasonic Powder Consolidation}

A CONDOR ultrasonic welding unit, shown in Figure 3.3 manufactured by STAPLA Ultrasonic Corporation, Wilmington, MA was used for the UPC experiments. This unit operates at a maximum power of $3.5 \mathrm{~kW}$ and a fixed frequency of $20 \mathrm{kHz}$. The controller unit transmits high frequency signals to the converter and the resulting vibrations are transmitted to the ultrasonic sonotrode through the booster unit and their amplitude can be a value between $4-9 \mu \mathrm{m}$ at a 2:1 ratio during the transmission as shown in Figure 3.4. The amplitude can be measured with the micro-gauge shown in Figure 3.3(a). The micro-gauge is connected to the machine by using a fixture. A uniaxial force is applied by using the $\mathrm{Z}$-axis positioning knob and measured through a calibrated Rubbermaid Pelouze 4040 digital scale whose load cell stage was mounted on the anvil. The welding parameters are adjusted by the controllers shown in Figure 3.3(c) and (d). There were two controllers that were used during the research. All copper specimens were consolidatey an old-type analog controller (D-65451) and all aluminum specimens were consolidated by a new digital controller (ST30). Both controllers provided the same welding conditions and parameters.
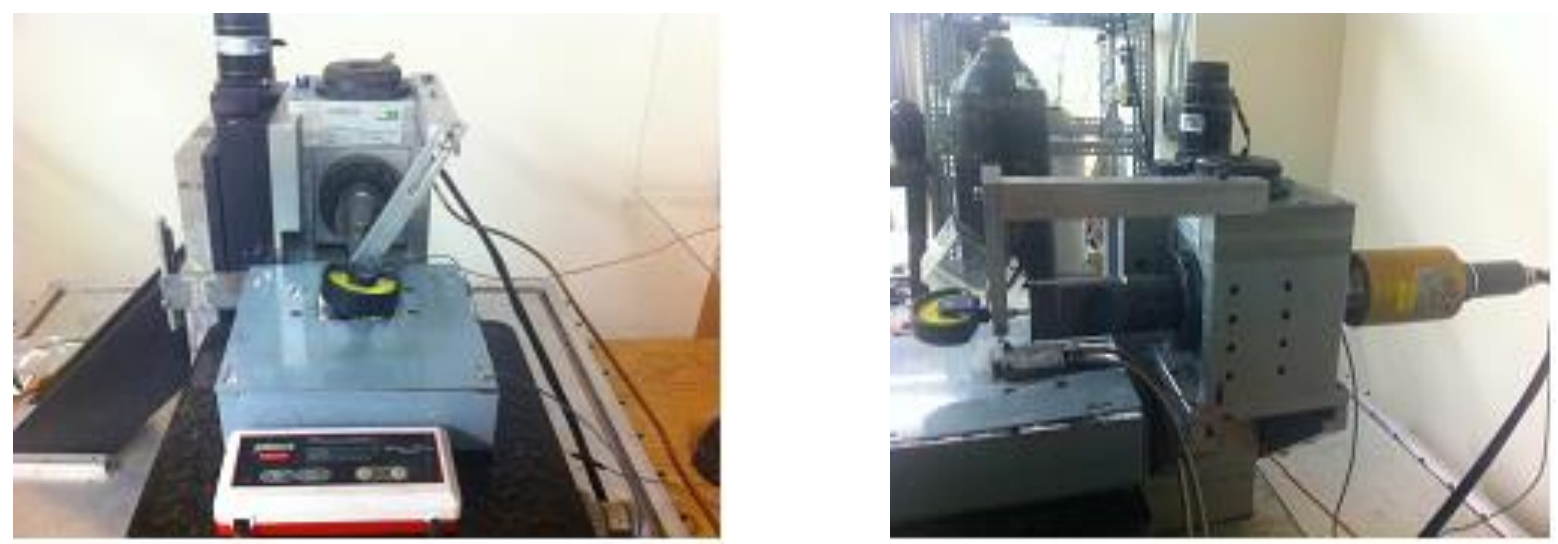

Figure 3.3: STAPLA Condor ultrasonic welding unit, (a) Front view, (b) Side view, (c)

Old control unit, (d) New control unit. 


\section{An Approach To Identify and Estimate The Bonding of Copper and Aluminum Powders, Karan Singh, Dr. Mohammad Israr,}

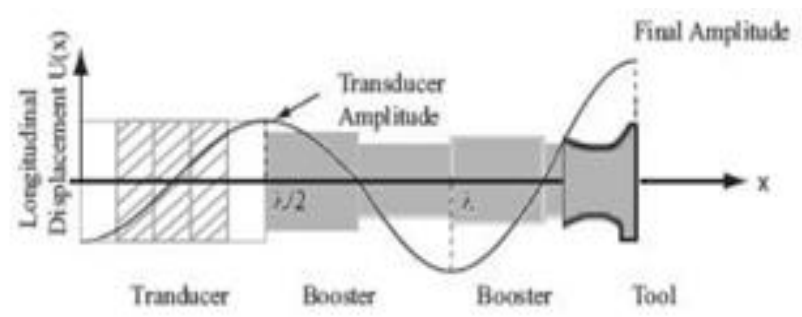

Figure 3.4: Amplitude enhancement of sonostrode due to booster configuration.

The sonotrode is made of high speed tool steel, so the maximum consolidation temperature is limited by the tempering temperature of the steel, and as such was kept below $500{ }^{\circ} \mathrm{C}$ in order to avoid softening of the sonotrode tip by over-tempering. The sonotrode tip has the size of $3.68 \mathrm{~mm} \times 3.68 \mathrm{~mm}$ with its surface machined into a $14 \times 14$ grid of knurls. To conduct experiments at elevated temperature, a heater plate was designed to be used with the ultrasonic welding unit. Two cartridge heaters from TUTCO which are $9.5 \mathrm{~mm}$ in diameter, $51 \mathrm{~mm}$ in length and $400 \mathrm{~W}$ in power and a K-type thermocouple probe from OMEGA are inserted in a stainless steel plate, .The heaters and the thermocouple are connected to a control box (Figure 3.7) which is controlled by a computer equipped with a National Instruments (NI) PCI-6035E multifunction data acquisition (DAQ) card through a NI BNC-2110 connector block..The computer program, which is coded on LabView 8.6, acquires the temperature data from the thermocouple and sends signals to the heaters to heat the plate to the set temperature.

Both copper and aluminum powders were consolidated under a uniaxial pressure and ultrasonic vibrations through a punch and die arrangement as shown in Figure 3.9. For copper consolidation experiments, the die was made of a $1.2 \mathrm{~mm}$ thick nickel plate with $4.3 \mathrm{~mm}$ die hole and the punch has the dimensions of $4.1 \mathrm{~mm}$ in diameter and $3.4 \mathrm{~mm}$ in thickness. For aluminum consolidation experiments, the thickness and hole diameter of the die were 1.16 $\mathrm{mm}$ and $3.66 \mathrm{~mm}$ respectively and the thickness and diameter of the punch were $1.83 \mathrm{~mm}$ and $3.56 \mathrm{~mm}$. The dies were tightly fitted into the die fixture with the powders being placed in it. For copper powder consolidation, a copper substrate which was $0.089 \mathrm{~mm}$ in thickness was placed under the die. For aluminum consolidation, a $0.025 \mathrm{~mm}$ nickel foil was placed under the die. For both metals, to prevent the powder from sticking of the powders to the punch, $0.025 \mathrm{~mm}$ thick nickel foil was placed between the punch and the powders.

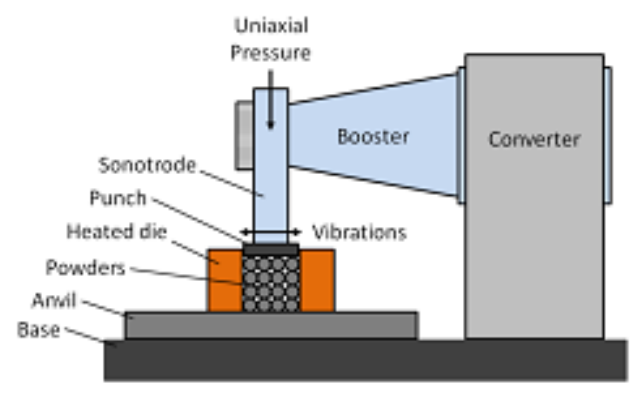

Figure: Schematic view of the UPC setup 


\section{An Approach To Identify and Estimate The Bonding of Copper and Aluminum Powders, Karan Singh, Dr. Mohammad Israr,}

After the materials and the punch and die arrangements were ready, the heaters were turned on to heat the whole assembly to the specified temperature which ranged from $473 \mathrm{~K}$ to $773 \mathrm{~K}$. The time that reaches the specified temperature was about a-b s. Then the welding sonotrode was lowered to apply a specified normal load on the punch ranging between 80 and $100 \mathrm{MPa}$. When the load settled to the set value, ultrasonic vibration was applied parallel to the die surface at a frequency of $20 \mathrm{KHz}$ with an amplitude of $9 \mu \mathrm{m}$ and duration of 1 to $4 \mathrm{~s}$. For aluminum, the whole process was done in air, and after consolidation, the die was cooled to room temperature, and ejected from the stage. Then the specimen was finally removed from the die. However, for copper, the same process was done in argon atmosphere. A large glove box, custom-designed and fabricated for the whole ultrasonic welding unit, was used to maintain the argon atmosphere .The glove box was evacuated by a rotary pump and backfilled with argon gas a few times.

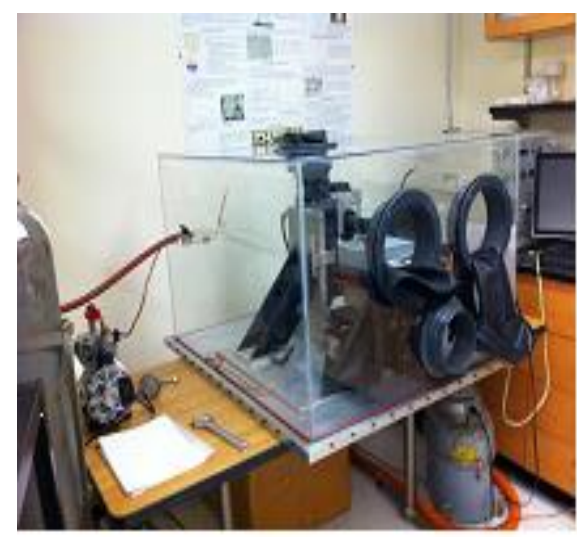

Figure: Custom-designed glove box.

\subsection{Metallographic Characterization and Microscopy}

After being removed from the die, the specimens were mounted in epoxy and cured for 30-40 minutes at room temperature. Then the specimens were ground on abrasive papers of different grit sizes $(400,600,1000,1200,1500,2000)$. Subsequent to grinding, the specimens were polished on buffing wheels with fine alumina powder with sizes of $1,0.3$, $0.05 \mu \mathrm{m}$. A Buehler ECOMET 5 two speed grinding-polishing table was used for the preparation of metallographic specimens. To see the microstructure and grain boundaries clearly, all copper specimens were etched by one part nitric acid and one part water for 35 seconds. The microstructural characterization of samples was done with an Olympus VANOX-T optical microscope and a JEOL JSM-6360 scanning electron microscope (SEM) ( $3 \mathrm{~nm}$ resolution at $30 \mathrm{kV}$ accelerating voltage).

\subsection{Porosity Measurements and Ultrasonic Washing Tests}

The porosity of the cross section is a good indicator of consolidation quality of the specimen. Since the specimen size is too small to apply the Archimedes' principle, porosity was determined by image analysis wiring, the software ImageJ. By counting the number of pixels that is associated with the porosities and dividing it by the total number of pixels in the image, ImageJ can calculate the area fraction of the porosities. Before the porosity calculation, to remove the contaminant on the cross section caused by 25 grinding and polishing, the specimens were washed in water by Fisher Scientific FS20D ultrasonic cleaner. 


\section{An Approach To Identify and Estimate The Bonding of Copper and Aluminum Powders, Karan Singh, Dr. Mohammad Israr,}

\subsection{Hardness Tests}

Vickers micro-hardness measurements were performed by using a Shimadzu HMV micro harness tester at loads of $245.2 \mathrm{mN}$ for copper and $98.07 \mathrm{mN}$ for aluminum, which corresponded to the Vickers micro hardness designations of HV 0.01 and HV 0.025. A loading time of $5 \mathrm{~s}$ was applied to all specimens.

\subsection{Bending Tests}

Just as well as the porosity measurements, manual bending tests can also measure the consolidation quality of specimens. The specimens were small, so half of every specimen was mounted in epoxy for metallographic characterization and the other half was manually bent with tweezers until it failed. Then the fracture surfaces of the specimens were examined by SEM to investigate the mode of fracture.

\section{ULTRASONIC POWDER CONSOLIDATION OF COPPER AND ALUMINUM PARTICLES}

Applying high strain rate deformation which allows for full-density consolidation at low to moderately elevated temperatures, UPC is a novel new technique for the consolidation of metal powders. Intense vibrations break and displace surface oxide layers and contaminants, thus facilitate full metal contact between powder particles and metallurgical bonding thereof. The softening effect observed in the ultrasonic welding of sheets and wires should also be promoting the deformation of metal powders, leading to high degrees of compact densification. This chapter addresses the production of copper and aluminum specimens by UPC. The UPC experiments were performed under different temperatures, pressures and ultrasonic consolidation time to investigate how these parameters affected the consolidation quality and under what conditions full-density consolidates could be achieved. Additionally, for the copper powder consolidation experiments, two different kinds of powders with different morphologies, dendritic and spherical, were used to investigate how the shapes of powders affected the consolidation results.

\subsection{Ultrasonic Consolidation of Copper Powder}

\subsubsection{Microstructural Analysis}

Figures 4.1 and 4.2 show the microstructures of copper specimens consolidated from dendritic and spherical powders, respectively, at 425 and $500{ }^{\circ} \mathrm{C}$ for $4 \mathrm{~s}$ under a uniaxial pressure of $84 \mathrm{MPa}$. The micrographs exhibit the microstructure changes of copper specimens caused by different consolidation temperatures. At $425{ }^{\circ} \mathrm{C}$, both the dendritic and spherical specimens show the particle shape and boundaries clearly, which indicates that densification was obtained but metallurgical bonding was not fully attained. At 500 the most particles were deformed and many of the prior particle boundaries disappeared, indicating better densification and a possible increase of metallurgical bonding. An increase in temperature reduces the material's yield point with the help of thermal activation to overcome the energy barrier for dislocation motion. This makes the powders easier to deform. Therefore, high consolidation temperature leads to higher degrees of densification and metallurgical bonding. However, there is also a difference between dendritic and spherical powders. The effects of temperature were less significant for the spherical powders than for the dendritic ones. Compared with dendritic ones, spherical powders in a compact 


\section{An Approach To Identify and Estimate The Bonding of Copper and Aluminum Powders, Karan Singh, Dr. Mohammad Israr,}

can more easily slide against each other, which suggests that they cannot be deformed as efficiently as dendritic ones. This explains why spherical specimens retain more original particle shape and boundaries at higher temperatures.
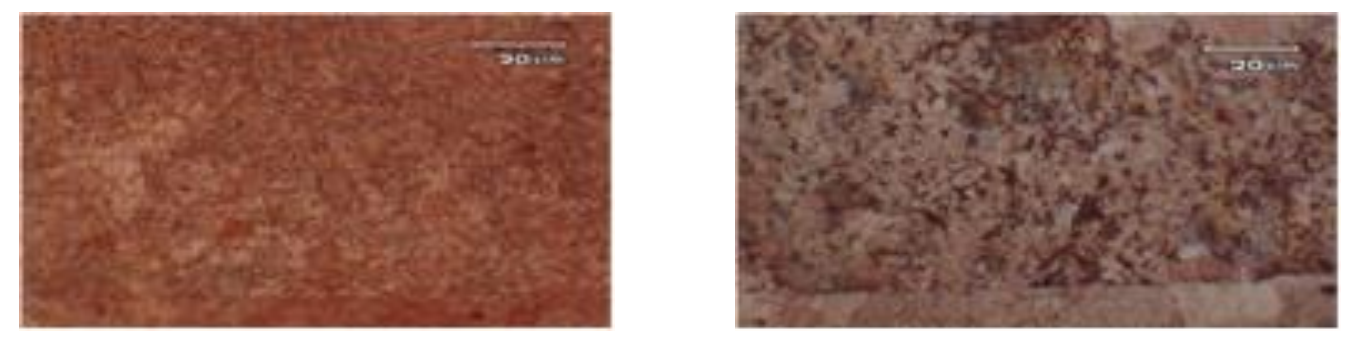

Figure 4.1: Optical micrographs of dendritic $\mathrm{Cu}$ powders consolidated under $84 \mathrm{MPa}$ for $4 \mathrm{~s}$ at temperature (a) 500, (b) 425
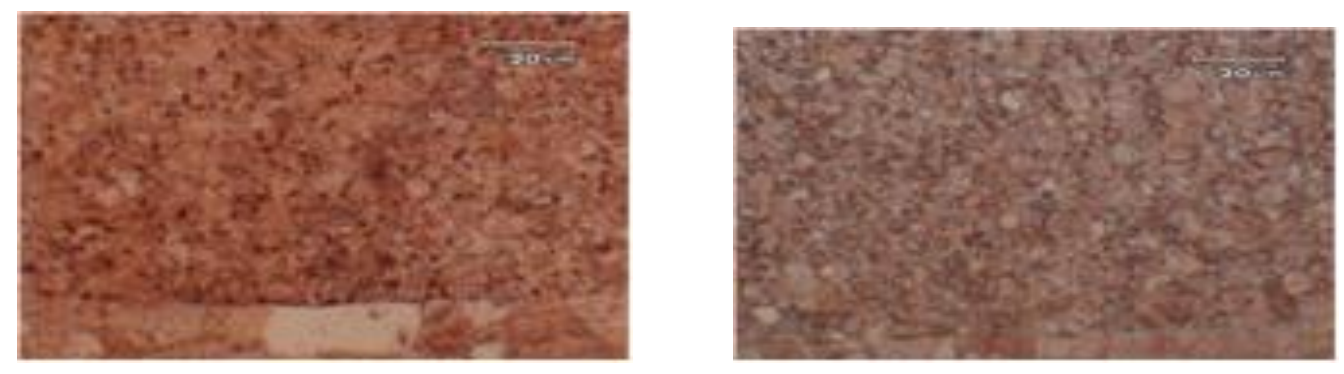

Figure 4.2: Optical micrographs of spherical $\mathrm{Cu}$ powders consolidated under $84 \mathrm{MPa}$ for $4 \mathrm{~s}$ at temperature (a) 500, (b) 425

Figures 4.3 and 4.4 show how pressure affected the dendritic and spherical copper powder consolidation at 500 and $4 \mathrm{~s}$. At the higher pressure of $100 \mathrm{MPa}$, both powder consolidates showed good densification and metallurgical bonding, especially for spherical powders. It is considered that the higher pressure of $100 \mathrm{MPa}$ restricted the slide of the spherical powders so that they can be deformed and bonded better than under $84 \mathrm{MPa}$. Figure 4.5 shows the effects of consolidation time on the consolidation quality. The longer consolidation time produced a much better performance than the shorter one indicating that the densification of the powder compact is a time-dependent process.
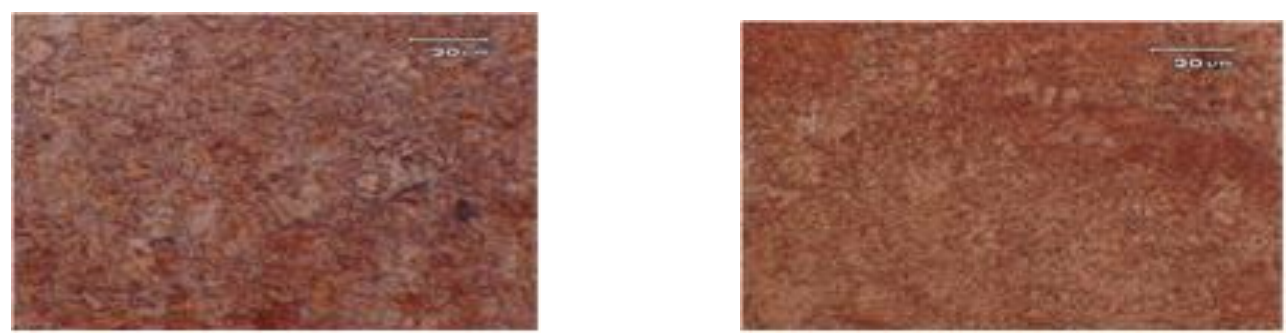

Figure 4.3: Optical micrographs of dendritic $\mathrm{Cu}$ powders consolidated at $500{ }^{\circ} \mathrm{C}$ for $4 \mathrm{~s}$ under pressure (a) $100 \mathrm{MPa}$, (b) $84 \mathrm{MPa}$. 


\section{An Approach To Identify and Estimate The Bonding of Copper and Aluminum Powders, Karan Singh, Dr. Mohammad Israr,}
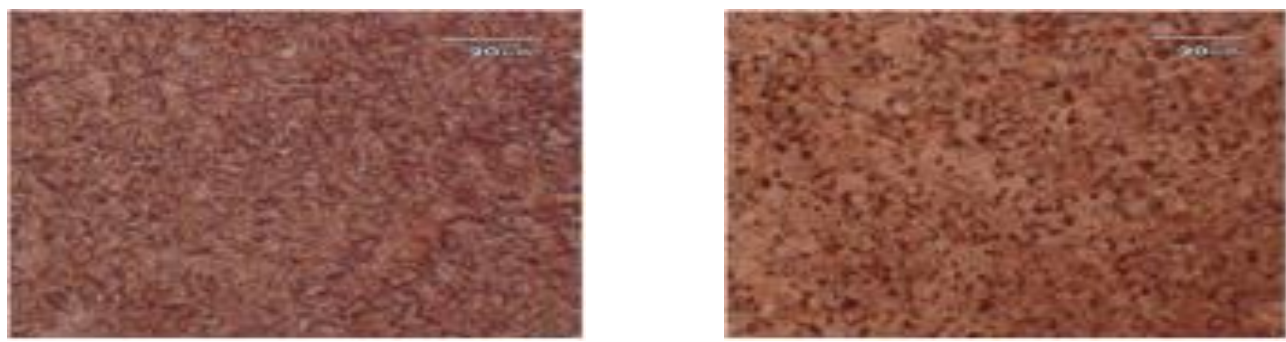

Figure 4.4: Optical micrographs of spherical $\mathrm{Cu}$ powders consolidated at500 ${ }^{\circ} \mathrm{C}$ for $4 \mathrm{~s}$ under pressure (a) $100 \mathrm{MPa}$, (b) $84 \mathrm{MPa}$.
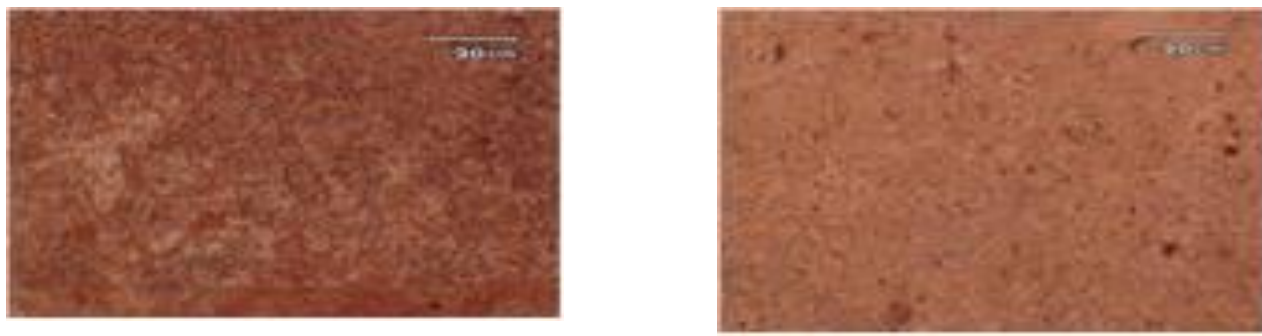

Figure 4.5: Optical micrographs of dendritic $\mathrm{Cu}$ powders consolidated at $500{ }^{\circ} \mathrm{C}$ under 84 MPa for (a) $4 \mathrm{~s}$, (b) $2 \mathrm{~s}$.

\subsubsection{Ultrasonic Washing Test and Porosity Measurements}

\subsubsection{The phenomenon of porosity increasing during ultrasonic washing}

Microstructural analysis can show how consolidation conditions affect the densification and bonding of powders, but it is only a qualitative observation. Porosity measurements of the cross section of consolidated specimens can show the consolidation quality in a quantitative manner. At first, ultrasonic washing in water was used to clean the cross section of the samples to avoid contaminants from grinding and polishing as shown in section 3.4. However, during this procedure, a new phenomenon was found that after different times of ultrasonic washing, different amounts of new pores appeared on the cross section as shown in Figures 4.6 and 4.7. With increasing washing time, the porosity increased initially and reached a constant value. This phenomenon indicates that under ultrasonic washing, some powder particles that were not compacted or bonded well came off the polished surface and those that were well bonded remained. As a result, this ultrasonic washing test was thought to provide a good means to study the extent of metallurgical bonding achieved in UPC and to see how the process parameters affected the consolidation. These measurements and tests were carried out for specimens consolidated under different processing conditions, as summarized in Tables 4.1-4.5. All as-consolidated specimens were ultrasonically washed in water for 2, 5, 10, 15 and 20 minutes. Optical micrographs were taken after each washing time and then were used to calculate the porosity by image analysis using the software ImageJ. 


\section{An Approach To Identify and Estimate The Bonding of Copper and Aluminum Powders, Karan Singh, Dr. Mohammad Israr,}
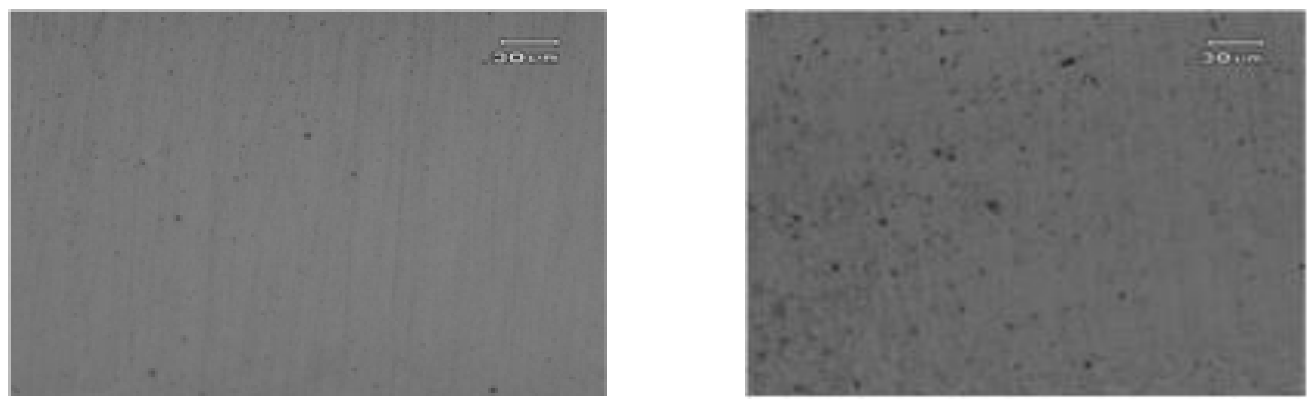

Figure 4.6: Optical micrographs of dendritic $\mathrm{Cu}$ powders consolidated under $500{ }^{\circ} \mathrm{C}$ and $4 \mathrm{~s}$ at pressure $84 \mathrm{MPa}$ (a) before ultrasonic washing, (b) after 20 min ultrasonic washing.
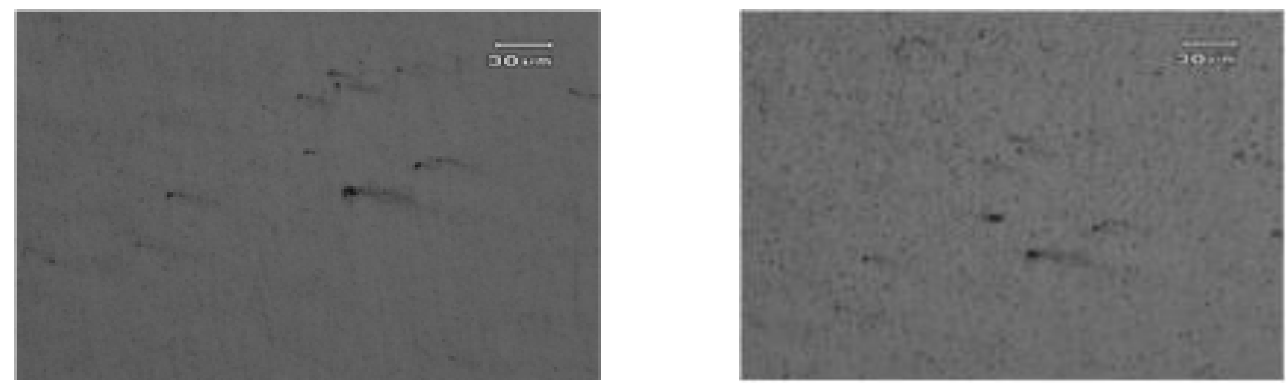

Figure 4.7: Optical micrographs of spherical $\mathrm{Cu}$ powders consolidated under 500 and $4 \mathrm{~s}$ at pressure $84 \mathrm{MPa}$ (a) before ultrasonic washing, (b) after 20 min ultrasonic washing.

\subsubsection{Porosity measurements and analysis for copper consolidated for $4 \mathrm{~s}$ under 84 MPa at different temperatures}

How the density of the dendritic copper specimens changed with ultrasonic washing time. The degree of densification, or density defined as " $100 \%$-porosity", is another way to express the quality of consolidation. With increasing ultrasonic washing time, the densities of all specimens decreased, which indicates that some powder particles which were not bonded well were removed from the specimens leaving pores. For dendritic powders consolidated for $4 \mathrm{~s}$ under $84 \mathrm{MPa}$, when the temperature was at and above 450 , both the densification and bonding of the powder were well-achieved as indicated by the high value of density above $98 \%$ even after a 20 minute wash. But for the specimen consolidated 425 the density decreased very quickly with increasing washing time. This means that the densification and bonding between dendritic powder particles were poor at 425 , and there should be a critical temperature between 425 and 450 above which good ultrasonic consolidation is achieved. The relationship between the density and consolidation temperature is shown in for specimens consolidated from the dendritic powder for $4 \mathrm{~s}$ under $84 \mathrm{MPa}$. The upper curve shows the density changes of as-consolidated specimens with respect to consolidation temperature. The lower curve shows the density changes of specimens that were after 20 minutes of ultrasonic washing. The upper one indicates that dendritic copper powder could achieve nearly full density $(\sim 100 \%)$ at and above $450{ }^{\circ} \mathrm{C}$, while at 425 the density stayed below $98 \%$. After 20 minutes of ultrasonic washing, the specimens consolidated at above 450 , still kept their density above $98 \%$, while the spe0cimen consolidated at 425 suffered a large decrease in density to less than $90 \%$. Thus, particle bonding was good in specimens consolidated at/above 450 , but was poor in specimens consolidated at 425 . 


\section{An Approach To Identify and Estimate The Bonding of Copper and Aluminum Powders, Karan Singh, Dr. Mohammad Israr,}

\subsubsection{Porosity measurements and analysis for copper consolidated under $100 \mathrm{MPa}$ for $4 \mathrm{~s}$ at different temperatures}

This section discusses ultrasonic copper powder consolidation under a higher uniaxial pressure of $100 \mathrm{MPa}$ for $4 \mathrm{~s}$ at temperatures of 300, 400, 450 and 500 . As shown in Figure 4.14 and 4.15 , at $100 \mathrm{MPa}$, the dendritic copper powder consolidated very well at and above 450 , with the as-consolidated densities ranging from $97-100 \%$. The specimen consolidated at 500 maintained very high density $(\sim 100 \%)$ even after 20 minutes of ultrasonic washing. The specimen consolidated at 450, too, kept a high density ( $98 \%)$ after washing. The specimen consolidated at 400 had a somewhat lower as-consolidated density $(\sim 97 \%)$ but suffered only a small loss of density during the ultrasonic washing, with the final density value above $96 \%$. The specimen consolidated at 300 also had a comparably high as-consolidated density of $97 \%$, but its density dropped rapidly below $91 \%$ during ultrasonic washing. This strongly suggests that attaining high degrees of densification does not necessarily translate into good metallurgical bonding. The above results indicates that producing high density consolidates with good inter-particle bonding requires a sufficient uniaxial pressure that permits the powder particles to deform and fill space which exposes fresh metal surface needed for metallurgical bonding. Powder particle repacking may be easier at lower uniaxial pressures, but its effect is less significant than that of powder deformation, particularly for dendritic powder particles.

\subsection{Ultrasonic Powder Consolidation of Aluminum Powders}

\subsubsection{Ultrasonic Washing Tests and Porosity Measurements}

The densifications and metallurgical bonding of Al specimens consolidated by UPC were also investigated through the same porosity measurement of ultrasonic washing procedure. Al specimens were consolidated under various conditions to study the effects of consolidation temperature and time. The uniaxial pressure was fixed at $80 \mathrm{MPa}$ and an air atmosphere was used for all of the experiments for aluminum.

\begin{tabular}{|c|c|c|c|c|c|c|}
\hline $\begin{array}{c}\text { Aluminum } \\
\text { Specimens }\end{array}$ & $\begin{array}{c}\text { Temperature } \\
\left({ }^{\circ} \mathrm{C}\right)\end{array}$ & $\begin{array}{c}\text { Pressure } \\
(\mathrm{MPa})\end{array}$ & $\begin{array}{c}\text { Time } \\
(\mathrm{s})\end{array}$ & $\begin{array}{c}\text { Punch } \\
(\mathrm{mm})\end{array}$ & $\begin{array}{c}\text { Die } \\
(\mathrm{mm})\end{array}$ & Atmosphere \\
\hline 1 & 350 & 80 & 1 & 3.56 & 3.66 & Air \\
\hline 2 & 300 & 80 & 1 & 3.56 & 3.66 & Air \\
\hline 3 & 250 & 80 & 1 & 3.56 & 3.66 & Air \\
\hline 4 & 200 & 80 & 1 & 3.56 & 3.66 & Air \\
\hline
\end{tabular}

\subsubsection{Hardness Tests}

The micro-Vickers hardness results of aluminum powder consolidation under the conditions shown in Tables 4.4 and 4.5. Comparison with the density results showed in Figures 4.27 and 4.33, respectively, shows that although the hardness of Al did decrease with decreasing consolidation temperature and time, the hardness and density curves do not show as striking similarities as those of the copper powder consolidations show before. This indicates that the hardness results of aluminum powder specimens are not entirely for related to the density. There might be other factors that influence the hardness of the aluminum specimens. Nonetheless, the hardness results still suggest that both temperature and consolidation time influence the attainment of densification and metallurgical bonding. 


\section{An Approach To Identify and Estimate The Bonding of Copper and Aluminum Powders, Karan Singh, Dr. Mohammad Israr,}

\subsubsection{Bending Tests}

The consolidated aluminum specimens were subjected to manual bending tests to evaluate the material ductility and examine the fracture surfaces. All specimens withstood $90^{\circ}$ bending tests to varying degrees at first. To break them to observe the fracture surface, these specimens need to be cut slightly on the edge and bent several times. This indicates that different degrees of metallurgical bonding were achieved for specimens consolidated at different conditions. Figure 4.36 shows the fracture surfaces of aluminum specimens consolidated at 400/300 for $1 \mathrm{~s}$ under $80 \mathrm{MPa}$. At 400, the fracture surface was more ductile than the surface at 300 as verified by the observation that the particle shape and boundaries were not discernible, while at 300, features indicative of particle boundaries and pores are seen on the surface. The fracture surfaces of aluminum powders consolidated at 300 for $2 \mathrm{~s}$ and $1 \mathrm{~s}$ under $80 \mathrm{MPa}$. At the longer consolidation time of $2 \mathrm{~s}$, a higher degree of the fracture surface exhibits much fewer features indicative of prior particles or pores.

\section{CONCLUSIONS}

UPC provides a viable route for the rapid consolidation of metal powders at low temperature under low pressure. This research focused on studying the densification and bonding of copper and aluminum powders in ultrasonic powder consolidation. For copper powder with dendritic and spherical morphologies, the minimum conditions for nearly full densification were determined to be $450{ }^{\circ} \mathrm{C}, 4 \mathrm{~s}$ and $84 \mathrm{MPa}$, with the best ones obtained at $500{ }^{\circ} \mathrm{C}$ for $4 \mathrm{~s}$ under $100 \mathrm{MPa}$. Dendritic copper powder specimens exhibited better densification and metallurgical bonding than spherical ones above $450{ }^{\circ} \mathrm{C}$ because they had to deform to a higher degree to fill the space between particles, hence creating more metal-tometal contacts for bonding formation. Spherical copper powder specimens produced better results below 450 due to their better packing geometry and better repacking under ultrasonic vibration. Application of higher uniaxial pressure makes the copper powder particles deform more readily to achieve higher densification while exposing more fresh metal-to-metal contact for metallurgical bonding. However, specimens consolidated under higher pressure but at lower temperature performed worse in terms of bonding, indicating that both fresh metal-to-metal contact surface and thermal activation are necessary for good metallurgical bonding. The degree of bonding increased with increasing consolidation time, indicating that bonding is a thermally activated process. The results of hardness tests show of that the hardness of copper powder 69 consolidates is largely proportional to their density. For aluminum, the best consolidation conditions were found to be 400, $2.5 \mathrm{~s}$ and $80 \mathrm{MPa}$. Within the testing range from 200 to 400 for $1 \mathrm{~s}$ under $80 \mathrm{MPa}$, aluminum specimens could achieve nearly full density above 350 and the density decreased with decreasing consolidation temperature below 350. After 20 minutes of ultrasonic washing, the density decreased almost the same amount ( 0.6 points) below the as-consolidated values, suggesting that the extent of compact densification correlates proportionally to the degree to which the metallurgical bonding is achieved in the Al specimens which is largely independent of temperature. The phenomenon that metallurgical bonding occurs almost as quickly as densification proceeds indicates that the rate of metallurgical bond formation is limited by the rate of creating fresh metal-to-metal contact in the compact. At $300{ }^{\circ} \mathrm{C}$ under $80 \mathrm{MPa}$ for different consolidation times ranging from 1 to $2.5 \mathrm{~s}$, the deformation of aluminum powder particles is timedependent. However, when subjected to ultrasonic washing, nearly the same amounts of mass loss happened for all of consolidated specimens regardless of consolidation time. This 


\section{An Approach To Identify and Estimate The Bonding of Copper and Aluminum Powders, Karan Singh, Dr. Mohammad Israr,}

confirms again that any fresh metal-to-metal contact caused by powder particle deformation translates almost directly to metallurgical bonding. In addition, the observed constant differences in density values between as-consolidated and after-washing specimens implies that oxide fragments persist at the aluminum powder particle boundaries, preventing full metal-to-metal contact, hence metallurgical bonding. 70 At $400{ }^{\circ} \mathrm{C}$ under otherwise identical conditions, densification was readily achieved within $1 \mathrm{~s}$, indicating the dependence of densification in time. The mass loss of 400 -consolidated Al specimens during ultrasonic washing decreased with increasing consolidation time, and was only 0.2 points for specimens consolidated for $2.5 \mathrm{~s}$. Thus, long consolidation times cause oxide fragments to move into and more uniformly distributed in the powder particle interior, thereby increasing metallurgical bonding. Further comparison of the data obtained at 300 and 400suggests that both densification and bonding are thermally activated processes. The hardness of aluminum specimens does not entirely correlate with the density. Nonetheless, the hardness results also suggest that both temperature and consolidation time affect the attainment of densification and metallurgical bonding.

\section{REFERENCES}

1. D. Erdeniz, "Characterizaion and Modeling of The Early-stage Reactions in Aluminum-Nickel Composites Produced by Ultrasonic Powder Consolidation," $\mathrm{PhD}$ dissertation, Northeastern University, Boston, MA, 2011.

2. T. Ando, I. E. Gunduz, P. Y. Wong and C. C. Doumanidis, "Vibratory Powder Consolidation," US Patent Office, US 2010/0003158, 2010.

3. E. Emeruwa, J. Jarriage, J. Mexmain and M. Billy, "Powder Compaction with Ultrasonic Assistance," Journal of Materials Science, Vol. 25, 1990, pp. 1459-1462.

4. E. S. Dvilis, O. L. Khasanov, V. M. Sokolov and J. P. Pokholkov, "Method for Compacting Powders into Articles and a Mold for Implenting the Method," US Patent Office, 6,919,041, 2005.

5. J. Tsujino, T. Ueoka, H. Suzuke, S. Shinuchi and K. Hashimoto, "Ultrasonic Vibration Press of Metal and Ceramics Powder Using Complex Vibration and Vacuum Condition," IEEE Ultrasonic Symposium, 1991, pp. 973-978.

6. I. E. Gunduz, "A Fundamental Study of Metal Structures and Properties in Ultrasonic Welding," PhD dissertation, Northeastern University, Boston, MA, 2006. .

7. F. Tavakoli-Dastjerdi, "Ultrasonic Materials Processing-with Applications to Powder Consolidation of $\mathrm{Cu}-\mathrm{Cr}$ Composites and Surface Hardening of Aluminum, Master Thesis, Northeastern University, Boston, MA, 2010.

8. H. V. Atkinson and S. Davies, "Fundamental Aspects of Hot Isostatic Pressing: An 72 Overview," Metallurgical and Materials Transactions A, Vol. 31A, 2000, pp. 29813000.

9. D. Hernandez-Silva, G. A. Herrera-Olvera and L. A. Barrales-Mora, "Consolidation of Ultrafine Grained Copper Powder by Warm Isostatic Pressing," Journal of Metastable and Nanocrystalline Materials, Vol. 20-21, 2004, pp. 189-194.

10. C. Y. Huang and G. S. Daehn, "Effect of Cyclic Pressure on the Low Temperature Consolidation of Several Composite Powder Systems," Acta Materialia, Vol. 45, 1997, pp. 4283-4296. 


\section{An Approach To Identify and Estimate The Bonding of Copper and Aluminum Powders, Karan Singh, Dr. Mohammad Israr,}

11. G. E. Korth and R. L. Williamson, "Dynamic Consolidation of Metastable Nanocrystalline Powders," Metallurgical and Materials Transactions A: Physical Metallurgy and Materials Science, Vol. 26 A, 1995, pp. 2571-2578.

12. E. Dunbar, N. N. Thadhani and R. A. Graham, "High-Pressure Shock Activation and Mixing of Nickel-Aluminum Powder Mixtures," Journal of Materials Science, Vol. 28, 1993, pp. 2903-2914.

13. P. M. Standring and J. R. Moon, "Application of Rotary Forging to Consolidation of Metal Powders," Powder Metallurgy, Vol. 35, 1992, pp. 193-202.

14. A. D. Rosato, Vreeland, Jr., T., and Prinz, F.B., "Manufacture of Powder Compacts," International Materials Reviews, Vol. 36, 1991, pp. 713-718.

15. J. E. Flinn, G. E. Korth, R. N. Wright and R. C. Green, "Dynamic Consolidation ofAluminum Powders," New York, NY, USA, 1986, pp. 45-61.

16. R. L. Hewitt, W. Wallace and M. C. de Malherbe, "Plastic Defo rmation in Metal 73 Powder Compaction," Powder Metallurgy, Vol. 17, 1974, pp. 1-12.

17. H. F. Lee, F. Boey, K. A. Khor and T. Sano, "High Deformation Consolidation Powder Metallurgy Processes for an Al-Li Alloy Composite," Materials Science and Engineering A, Vol. A189, 1994, pp. 173-180.

18. Y. Kawamura, A. Inoue, K. Sasamori and T. Masumoto, "Consolidation Mechanism of Aluminum-Based Amorphous Alloy Powders During Warm Extrusion," Materials Science and Engineering A, Vol. 181-82, 1994, pp. 1174-1178.

19. M. Galanty, P. Kazanowski, P. Kansuwan and W. Z. Misiolek, "Consolidation of Metal Powders During the Extrusion Process," Journal of Materials Processing Technology, Vol. 125-126, 2002, pp. 491-496.

20. Y. Seung Chae, N. Do Minh, H. Sun Ig, H. Zenji and K. Hyoung Seop, “Achieving Both Power Consolidation and Grain Refinement for Bulk Nanostructured Materials by Equal-Channel Angular Pressing," Key Engineering Materials, Vol. 2007, pp. 2298-2308.

21. Z. Jin-Yuan, A. Baoren, L. Chunlan, Z. Ruizhen, Z. Dengxia and M. Chenghui, "Microstructures of Explosively Consolidated Rapidly Solidified Aluminum and AlLi Alloy Powders," Journal of Materials Science, Vol. 27, 1992, pp. 2298-2308.

22. Jellison J. L., Albright C. E., Devine J., Harmon G., Knorovsky G. A., Winchell V.H., Papritan J.C., "Ultrasonic Welding," Welding Handbook, Ch. 25, 8th edition, O’Brien R. L. ed, American Welding Society, Miami FL, 1991. 74

23. Papanikolaou G., "Rapid Manufacturing of Mesoscale Structures through Ultrasonic Welding," Tufts University, Master Thesis no. 6136, 2002.

24. Weiss B., "The Defect Structure of Ultrasonically Fatigued Fcc Metals," Proceedings of the First International Symposium on High-Power Ultrasonics, p. 36, 1970.

25. Awatani J., Katagiri K., Bulletin of ISME, Vol. 12, p. 10, 1969.

26. Joshi K., "Formation of Ultrasonic Bonds Between Metals," The Welding Journal, p. 840, December 1971.

27. Harman G. G., Leedy K. O., "An Experimental Model of the Microelectronic Wirebonding Mechanism,” IEEE Reliability Physics Proceedings, p. 49, 1972.

28. Maurer K0. L., "Electron Microscope Observation on Fatigue and Ultrasonic Fatigue in Metallic Materials," Proceedings of the First International Symposium on HighPower Ultrasonic, p. 53, 1970. 


\section{An Approach To Identify and Estimate The Bonding of Copper and Aluminum Powders, Karan Singh, Dr. Mohammad Israr,}

29. Gunduz I. E., Ando T., Shattuck E., Wong P. Y., Doumanidis C. C., "Enhanced Diffusion and Phase Transformations during Ultrasonic Welding of Zinc and Aluminum," Scripta Materialia, Vol. 52(9), p. 939, $2005 .$.

30. Pogodin-Alekseev G. I., "Ultrasonic Welding," The Welding Journal, Vol. 35(8), p. $761,1956$.

31. Shankar Suthar, Mangesh Kumar Chauhan and Dr. Mohammad Israr, "Investigation and Analysis of Diesel Engine Using Bio Diesel" International Journal of Mechanical Engineering \& Technology (IJMET), Volume 6, Issue 2, 2015, pp. 56 - 61, ISSN Print: 0976 - 6340, ISSN Online: 0976 - 6359.

32. T. Prabhu And Mr. A. Arulmurugu, "Experimental And Analysis of Friction Drilling on Aluminium and Copper" International Journal of Mechanical Engineering \& Technology (IJMET), Volume 5, Issue 5, 2014, pp. 130 - 139, ISSN Print: 0976 6340, ISSN Online: 0976 - 6359.

33. Brajraj Singh, D C Gupta, R. Chaudhary, K.Singh and Y M Gupta, "Strong Coupling Model For High-TC Copper-Oxide Superconductors" International Journal of Advanced Research in Engineering \& Technology (IJARET), Volume 4, Issue 1, 2013, pp. 134 - 141, ISSN Print: 0976-6480, ISSN Online: 0976-6499.

34. T. Balamurali and B. Preetha, "The Separation of Copper, Nickel and Chromium Metal Ions Using with Ultrafiltration Membrane: Effect of Polymer Membrane Compositions" International Journal of Advanced Research in Engineering \& Technology (IJARET), Volume 5, Issue 6, 2014, pp. 144 - 162, ISSN Print: 09766480, ISSN Online: 0976-6499. 